\section{Plasma cholinesterase deficiency in a premature neonate}

\section{To the Editor:}

We read with interest the recently published case report of Pasquariello and Schwartz ${ }^{1}$ describing what they believed to be the youngest reported case of prolonged apnoea after the administration of succinylcholine in a twoday-old full-term infant. We recently had a similar case which we believe to be even younger. A four-week-old premature infant (born at 32 wk gestational age) presented for bilateral inguinal hernia repair.

The infant weighed $2.8 \mathrm{~kg}$ and had progressed well since birth with no complications. He was anaesthetized with halothane and nitrous oxide in oxygen. Atropine $0.1 \mathrm{mg}$ and succinylcholine $6 \mathrm{mg}$ were administered following establishment of intravenous access to facilitate tracheal intubation. Difficulty was experienced weaning the patient from mechanical ventilation about $50 \mathrm{~min}$ later. Neuromuscular testing confirmed absence of response to single-twitch and tetanic stimulation. Two and a half hours later a weak response to tetanic stimulation was present, spontaneous eye opening occurred four hours after the administration of the succinylcholine and the trachea was extubated after eight hours.

The plasma cholinesterase level was $11 \mathrm{U} \cdot \mathrm{L}^{-1}$ (normal $3000-9300$ ). The activity was too low to determine a dibucaine or fluoride number. The very much lower level of plasma cholinesterase activity seen in this case compared with that of Pasquariello and Schwartz may represent a different silent gene variant. ${ }^{2}$

The very low frequency of the "atypical" allele in the Black Southern African populations has previously been reported. ${ }^{3}$ Succinylcholine associated apnoea is rarely seen and when it does occur one is reasonably sure that this is due to the homozygous silent gene variant as was evident in this case.

\author{
A Roux FFA \\ J.M. Ansermino FFA \\ Department of Anaesthesia \\ Johannesburg Hospital \\ Johannesburg \\ South Africa
}

\section{REFERENCES}

1 Pasquariello CA, Schwartz RE. Plasma cholinesterase deficiency in a neonate. Can J Anaesth 1993; 40: 529-31.

2 Whittaker $M$. Plasma cholinesterase variants and the anaesthetist. Anaesthesia 1980; 35: 174-79.
3 Krause $A$, Lane $A B$, Jenkins T. Pseudocholinesterase variation in southern African populations. SAMJ 1987; 71 : 298-301.

\section{$R E P L Y$}

The report by Roux and Ansermino reminds us that plasma cholinesterase needs to be considered in the differential diagnosis of prolonged perioperative apnoea in all age groups, including the premature neonate. In our institution, succinylcholine is administered only if a specific indication for its use is present. Consequently, we reserve it for rapid sequence induction, laryngospasm, and for very short cases (such as a single pass bronchoscopy). Despite its limited use, we may discover many cases of plasma cholinesterase deficiency in small babies due to the large number of premature infants that are currently surviving. In addition, prolonged perioperative apnoea may be seen in patients who receive mivacurium, a new relaxant also metabolized by plasma cholinesterase. ${ }^{1,2}$ Any future reports of even younger patients with plasma cholinesterase deficiency will be lefi to thase physicians caring for fetuses undergoing in utero surgery!

C.A. Pasquariello MD

R.E. Schwartz MD

Department of Anesthesia and Critical Care

Temple University School of Medicine

Philadelphia, Pa.

\section{REFERENCES}

1 Ostergaard D, Jensen E, Jensen FS, Viby Mogensen J. The duration of action of mivacurium-induced neuromuscular block in patients homozygous for the atypical plasma cholinesterase gene. Anesthesiology 1991; 75: A774.

2 Petersen RS, Bailey PL, Kalameghan R, Ashwood ER. Prolonged neuromuscular block after mivacurium. Anesth Analg 1993, 76: 194-6.

\section{Laryngoscope blade shape}

To the Editor:

I address this letter to congratulate you on your investigation as published in the Can J Anaesth 1993; 40: $262-70$

There is no doubt that this type of analysis is of immense service to manufacturers as well as the physician anesthetist.

I do have some question about the statements about the blade tip engaging the hyoid bone. Reference is constantly made to Professor Chevalier Jackson's report. However, no notation is made to the fact that Jackson's 1913 publication referred to a straight blade laryngoscope tip with an elongated bevel, which was ovoid in shape and of circumferential tubular design. Also, that this instrument was not tapered and did not have a deflection distally as now found on the Miller and Snow blades. Also, his technique involved placement of the blade in the oesophagus, and then retraction until the oesophageal introitus dropped from sight. Thus, we had the tip far beyond the epiglottis. This is not the technique generally 